\title{
Rape as an adaptation
}

\section{Is this contentious hypothesis advocacy, not science?}

\section{A Natural History of Rape: Biological Bases of Sexual Coercion \\ by Randy Thornhill \& Craig T. Palmer MIT Press: 2000.272 pp. \$28.95, £17.95 \\ Jerry A. Coyne and Andrew Berry}

In A Natural History of Rape, Randy Thornhill and Craig Palmer argue that rape is an adaptation - that it has evolved to increase the reproductive success of men who would otherwise have little sexual access to women. Their analysis of rape then forms the basis of a protracted sales pitch for evolutionary psychology, the latest incarnation of sociobiology: not only do the authors believe that this should be the explanatory model of choice in the human behavioural sciences, but they also want to see its insights incorporated into social policy. Thus, in a single, slim volume, Thornhill and Palmer give us both an inflammatory analysis of a sensitive topic, and a manifesto outlining evolutionary biology's future conquest of the social sciences.

In the furore that has greeted the book's publication, the scientific evidence for the authors' arguments has been largely ignored. However, it is here that we must start. If their specific claims about rape are not scientifically sound, then the authors' grand vision of the centrality of natural selection to every aspect of our behaviour collapses as well. In their media appearances, Thornhill and Palmer cloak themselves in the authority of science, implying that the controversy over their ideas is purely political, and that the underlying biology is unimpeachable. This is a serious misrepresentation.

What persuasiveness the book does possess rests on an ingenious rhetorical trick. The authors lay out two alternative evolutionary hypotheses: rape is either a 'specific adaptation' (that is, natural selection explicitly promoted the act) or a 'by-product of evolution' (there was no direct selection for rape; rather it is an accidental product of selection for, say, male promiscuity and aggression). Readers unconvinced by the specific-adaptation argument therefore find themselves embracing by default the byproduct alternative. Either way, Thornhill and Palmer claim a convert.

But what, in behavioural terms, is an evolutionary by-product? Everything that is not a specific adaptation. Thus, playing the piano - an activity unlikely to have been instrumental in the evolution of the brain is an evolutionary by-product, because it depends on a brain that was itself produced by natural selection. If every human behaviour can be seen as a by-product of evolution, then the by-product idea is useless, for a theory that explains everything is merely a truism. The claims that rape and playing the piano are by-products of evolution are claims without content.

It is not surprising, then, that A Natural History of Rape is largely an argument for the specific-adaptation theory. The authors' evidence, however, either fails to support their case, is presented in a misleading and/or biased way, or equally supports alternative explanations. The following examples illustrate each of these failings.

First, Thornhill and Palmer make much of the claim that rape victims tend to be in their prime reproductive years, suggesting that reproduction is indeed a central part of the rapist's agenda. But the data they present contradict this claim. In a 1992 survey that attempted to deal with the substantial statistical problem of unreported rape, $29 \%$ of US rape victims were under the age of 11 . As that age group comprises approximately $15 \%$ of the female population, under-11s were overrepresented among rape victims by a factor of two. So invested are the authors in their specific-adaptation hypothesis that they try to explain this non-adaptive anomaly by noting that the data do not indicate the "proportion of the victims under 11 who were exhibiting secondary sexual traits". Further, "the increasingly early age of menarche in Western females contributes to the enhanced sexual attractiveness of some females under 12". In the end, the hopelessness of this special pleading merely draws attention to the failure of the data to support the authors' hypothesis.

Second, the authors contend that, based on sociological studies, female rape victims of reproductive age are more traumatized by the experience than are women either too old or too young to reproduce. The rationale is that reproductive-age women are in effect mourning the lost opportunity for mate choice which rape, in the world view of evolutionary psychology, represents to them. The authors see this apparent heterogeneity in the reaction to rape as supporting their claims about the reproductive essence of the act.

In checking the cited reference (one of its authors is Thornhill himself), we find that the original work's conclusions differ

\section{A celebration of Egyptian history}

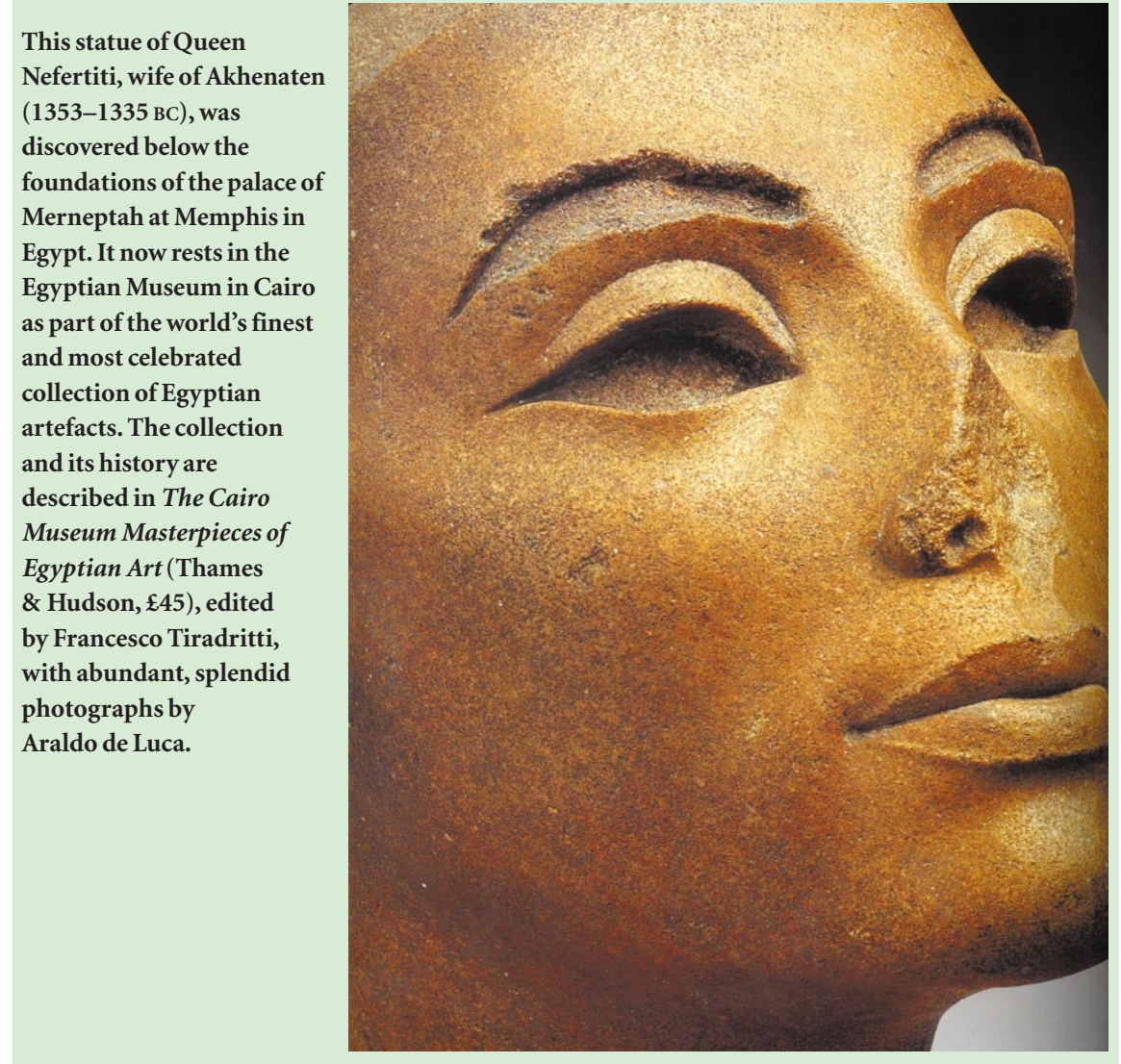


critically from those given in the book. According to Thornhill and Palmer, the cited study shows post-rape trauma to be higher in reproductive-age women (age 12-44) than in the two other age classes (under 12 and over 44). In fact, the data show that the only heterogeneity in response to rape comes from the under-12 class: the over-44 class is just as traumatized as the $12-44$ one. However, when the over- 44 and under- 12 classes are pooled, the under-12 effect of less trauma makes this combined 'non-reproductive' class significantly different from the 12-44 one. The authors have used statistical sleight of hand to buttress their argument. And we need hardly point out that the relative lack of trauma in the youngest age group may be unrelated to sexual immaturity: rather, children may be less able to express their feelings. Furthermore, the original study's data are questionable because much of the assessment of trauma in the under- 12 class was necessarily based on reports from the child's care-givers rather than from the child herself. Direct comparison of observer-reported and selfreported data on such a subjective issue is extremely problematic.

Finally, the fact that women of reproductive age experience more violence during rape than do older women or children suggesting that they fight back harder - is taken by the authors as evidence that they have more to defend. There is, they contend, more at stake - reproduction, no less - for reproductive-age women. While it is true that women of reproductive age who resist

rape may be partly motivated by the fear of unwanted conception, it is also true that such women, at the peak of their bodily strength, are most physically capable of fighting back. Children cannot fight off a full-grown man, and older women may also find resistance beyond them. In exclusively championing their preferred explanation of a phenomenon, even when it is less plausible than alternatives, the authors reveal their true colours. A Natural History of Rape is advocacy, not science.

We have highlighted just three examples of the book's flawed arguments. There are many more. The evidence that rape is a specific adaptation is weak at best. In keeping with the traditions established early in the evolution of sociobiology, Thornhill and Palmer's evidence comes down to a series of untestable 'just-so' stories.

Sociobiological approaches to human behaviour may yield interesting insights. But it is disciplinary hubris - a long-standing feature of evolutionary psychology - to suppose that natural selection underlies our every action. Because of the central role of reproduction in Darwin's theory, sexual behaviour is, in principle, a good candidate for fruitful sociobiological study, but even here it usually fails dismally. The most imaginative and committed sociobiologist would be hard-pressed to show that masturbation, sadomasochism, bestiality, and pornography's enthusiasm for high heels are all direct adaptations. In its insistence on forcing everything into the strait-jacket of adaptation, evolutionary psychology offers a
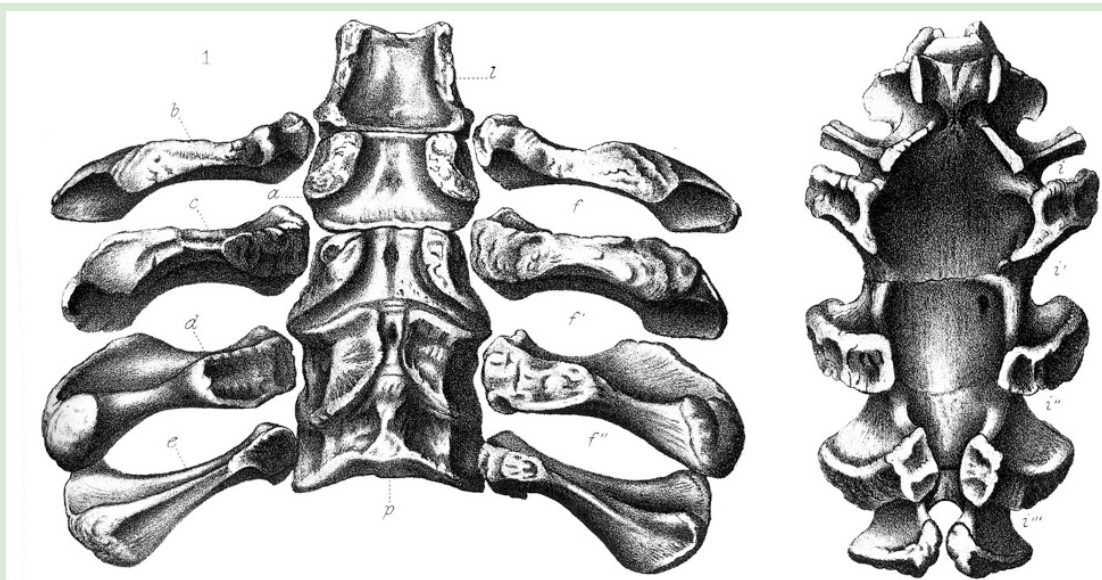

\section{New lease of life for a dinosaur prize}

Como Bluff in southern Wyoming was the site of the world's first major discovery of dinosaur remains. Othniel Charles Marsh, a palaeontologist for Yale University's Peabody Museum, financed the dig and claimed a large proportion of the fossils excavated. $\mathrm{He}$ reunited the excavated bones and had lithographs made of them. The story of his achievements was chronicled in 1966 in a classic book, Marsh's Dinosaurs: The Collections from Como Bluff by John H. Ostrom and John S. McIntosh. Most of the lithographs were also reproduced (an example, two views of a Stegosaurus sacrum, is shown above). The book has long been out of print, but is being reissued this month (Yale University Press, \$85), with a foreword by Peter Dodson which places the discovery in historical perspective. woefully incomplete perspective on human behaviour. Thornhill and Palmer have inadvertently revealed just how deficient that perspective is.

Jerry A. Coyne is in the Department of Ecology and Evolution, University of Chicago, 1101 East 57 Street, Chicago, Illinois 60637, USA.

Andrew Berry is at the Museum of Comparative Zoology Labs, Harvard University, 26 Oxford Street, Cambridge, Massachusetts 02138, USA.

\section{Amassing the case for the defence}

\section{Evolutionary Catastrophes: The}

\section{Science of Mass Extinctions}

by Vincent Courtillot

Cambridge University Press: 1999. 173 pp. $\mathfrak{£} 14.95$

\section{Douglas Palmer}

Scientists who are not geologically minded may be puzzled by the apparent inability of geologists to agree on whether the dinosaurs, ammonites and their ilk were or were not 'polished off' 65 million years ago by the impact of an extraterrestrial bolide. Some geologists, such as Walter Alvarez and his father, Nobel prizewinning physicist Luis Alvarez, have argued vehemently for an impact event in the area of today's Yucatan peninsula in Mexico as the nemesis. In Evolutionary Catastrophes, Vincent Courtillot promotes large-scale vulcanicity as the driving force behind this and other major extinction events.

Courtillot acknowledges the occurrence of the impact event at the 65 million-yearold Cretaceous/Tertiary (K/T for short) boundary. But he questions whether it was the impact event or, instead, massive and prolonged contemporaneous eruption of the Deccan lavas in India which really caused the extinction.

Courtillot extends the argument to the other four large extinction events of the past 450 million years of Earth's history. He points out that the K/T event is the only one of five major extinctions to have a well-established link to an extraterrestrial impact big enough to cause environmental damage on a global scale. Instead, he argues that large-scale vulcanicity is a more likely cause, not only at the K/T boundary, but also in three of the four other major extinctions, including the biggest of them all, the PermoTriassic event. During this latter extinction, 248 million years ago, it is estimated that $95 \%$ of fossil species were wiped out over a period of two million years or so, including some $60 \%$ of marine families and $63 \%$ of tetrapod families.

Nobody now seriously denies that a major impact event occurred at the end of 